\title{
Coordination of Visual Culture and Art Education
}

\author{
Juan Tan \\ Sichuan Vocational \& Technical College, Suining, 629000, China
}

Keywords: visual culture; art education; collaboration; research methodologies

\begin{abstract}
In the past, traditional art education focused too much on cultivating students' visual styling skills, and paid less attention to cultivating students' visual performance and visual analysis ability. For art disciplines, several major knowledge modules, such as art criticism, art history, art creation, and aesthetics, should be integrated in the teaching process to improve the students' knowledge structure as much as possible and improve their artistic quality. Visual culture not only marks the transformation of human cultural patterns, but also means the change of human cognitive style, thinking style and even ideology. People's visual objects have become more and more diverse, visual experiences have become more sophisticated, and visual concepts have also undergone great changes, and their visual capabilities have also been greatly improved.
\end{abstract}

\section{Introduction}

With the continuous innovation and development of modern science and technology in China, the media is constantly being updated. People's living space is filled with various images, such as games, television, movies, animation, networks, videos, advertisements, etc. Going home to experience the excitement and fun of these images will help enrich people's lives and emotional experiences. At present, visual images are important ways for people to receive information from outside, better experience life, and shape their own temperament. However, visual images are of different types, how to identify excellent visual images, correctly judge the value of visual images and aesthetic culture, and improve themselves. The visual literacy and the cultivation of its own visual forms are the educational responsibilities that contemporary art education should undertake.

Vision is the most important way for human beings to know the world and acquire information. The vast majority of people's grasp of information in the external world is obtained through vision, and it is also the most perceptive form of human beings receiving information. It distinguishes two features of color and shape. Visual language is based on two-dimensional or three-dimensional space material. Its expression is based on the visual system composed of various visual forms and colors to express information content. The perceptual way of visual language is to observe, read through the eyes, through the eyes, the optic nerve and the brain. Visual elements such as points, lines, faces, textures, and colors are effectively selected and adjusted in accordance with the needs of specific information. The strength of the expression of visual language is not only related to the content of the content of visual language information and the form of transmission, but also related to the method of 
reading and understanding of visual language by the receiver of visual language information. Reading methods and understanding directly affect the visual language's judgment results and understanding. The most basic method of visual language reading is association, which can arouse viewers' imagination and thoughts and feelings about visual phenomena.

The traditional art education is mainly based on elite arts, and the field and scope of art education are relatively narrow. However, under the background of modern times, artistic forms are becoming more and more abundant, and the art transmission methods are also gradually increasing. The traditional single art classroom teaching has been also inability to maintain consistency with contemporary forms of visual expression has, to a large extent, affected the role of art education in the development of people. Therefore, under the influence of visual culture, we should widen the scope of traditional elite art visual exploration, extend art education classrooms to campuses, art galleries, art districts, communities, and even society, pay more attention to visual images in people's daily lives, and expand contemporary art. The focus of education is to realize the open teaching of contemporary art education.

With the rapid development of network computer technology, various advanced information technologies are widely used in various fields of social production and people's lives. The sharing of information resources is getting higher and higher, providing many visual resources for contemporary art education and teaching. Visual information such as video, animation, and graphics is the main form of visual culture. It is mainly transmitted to people through the medium of media. As McLuhan said, "the media is also information." To spread these media information, you must Relying on modern information technology. Multimedia-assisted instruction can convey these visual cultures vividly and vividly to students. Compared with traditional teaching methods, it is more convenient and flexible. In the process of contemporary art education, you can use the network information platform as a carrier to efficiently combine visual information and music. Art education in the form of words enhances the vividness and intuition of classroom teaching.

\section{The Proposed Methodology}

\subsection{Definition of visual culture.}

Culture refers to spiritual and material products such as human activities, ways of thinking, and lifestyles. It is the general term for a nation's long-term lifestyle. It is a heterogeneous culture of different nationalities living in different regions and different lifestyles. Simultaneous generations of contemporary life style and production development spirit and material production as culture covers all art forms including music, art, literature, film, electronic media, and dance. All forms of culture that are closely related to our vision can be called visual culture.

Culture and economy are closely linked. In the past, there was a division between the upper culture and the lower culture, which included social competition in daily life. In a changing society, culture gained new meaning. Visual culture involves the experience of relying on visual senses and the care and appeal of people, and uses images and texts to communicate. If we separate the vision and culture, we cannot explain the true meaning of visual culture. Visual culture is based on the social and economic trends of a certain era and diverse lifestyles. It is a culture that uses image symbols as elements and visual perception as external expressions.

The scope of visual culture determines the diversity of visual culture definitions. Foreign theoreticians classify visual culture into four forms: first, to focus on visual aspects; second, to emphasize social themes; third, to combine visual aspects and social context; and fourth, to combine reality with theory. 
Images affect our lives. Social speech and images are related. If there is no theme in the image, the image will only be painted on the canvas; if there is a theme, it will become a work of art. In the visual culture, the themes revealed in the works have become the central idea. The topics here include politics, culture, regions, society and schools as the emotions, insights, beliefs, etc. that the students see and the heart have also become the conditions and environment for students to paint.

Based on the definition of visual culture by some scholars, we can think that visual culture is a theme-centered image that is centered on sensory experience in the social culture and appears through the visual media. Therefore, visual culture should be understood in combination with various viewpoints.

\subsection{Art education.}

In the past, the traditional branch of art education was very specific and detailed, and the orientation of education was relatively single. The main subjects of teaching practice included sketching, anatomy, perspective, sketching, and coloring. The importance attached to the appreciation of Chinese and foreign classical works of fine arts was cultivated, resulting in students' knowledge. Very narrow, more one-sided knowledge. At present, the artistic expression forms and artistic carriers are gradually diversified and diversified. We can not only read visual information in the fields of architecture, painting, and sculpture, but also can learn from places such as electronic media, arts, and popular arts. For the first time, DBAE proposed that four art disciplines should integrate aesthetics, art criticism, art history, and art creation. Since the idea was put forward, American scholar Paul Duncan believed that art education should adopt integrated art education and advocated visual culture and art education. This concept of art education accommodates various cultural industries. In art education, flow culture and popular culture were also added, which enriched the form, connotation and essence of art education, promoted the diversified development of art education, and broadened the teaching scope of art education.

For art disciplines, several major knowledge modules, such as art criticism, art history, art creation, and aesthetics, should be integrated in the teaching process to improve the knowledge structure of students and improve their artistic quality. At the same time, we should realize the interrelationship between contemporary art and other humanities disciplines, constantly improve the diversity of art education discipline construction, and innovate the path of art education. Change the traditional technology-based art education, increase the humanities education, and enrich the students' cultural and historical heritage.

\subsection{Developing students' visual quality.}

In the past, traditional art education focused too much on cultivating students' visual styling skills, and it paid less attention to cultivating students' visual performance and visual analysis ability. De Beers once put forward such a viewpoint, "We should change the traditional concept of art education as attach importance to the development of students' visual thinking, visual communication, visual understanding and other comprehensive visual abilities." Generally speaking, visual literacy mainly includes three parts: visual learning, visual communication, and visual thinking. The main purpose of visual learning is to enable students to recognize various visual form elements, develop students' ability to perceive the beauty of visual forms, and master the combination of visual forms. Some intrinsic laws can profoundly recognize the connotation and imagery of the visual form, so that students can rationally analyze and judge when they are exposed to various visual images, and truly understand their meaning and content, and form a visual form of their own. Language style can convey your inner feelings and ideas. The main purpose of visual communication is to allow people 
who receive visual information such as graphics and drawings to feel the thoughts or concepts they want to convey, and to ensure the effectiveness of visual communication.

In summary, in the wave of visual culture development, the concept of visual culture has been actively introduced in contemporary art education is an inevitable choice to adapt to the development and progress of the times. Teachers should make full use of modern information technology to then implement open and diversified teaching methods, achieve multi-disciplinary and multi-professional interdisciplinary teaching, and focus on cultivating students' visual quality to improve the students' comprehensive ability in humanities, form their own unique visual language form, express their own inner feelings and ideas.

\subsection{Visual cultural education background.}

In multicultural art education, fine art is not simply a product of modeling, it is a reflection of a historical and social system, and it is a tool to provide cultural value. Through the diversity of art, you can understand other cultures. The content of diversified art education includes the category of art excluded from the tradition of Western centralism according to the modeling elements and principles. Ethnic arts, primitive arts, female arts, and popular arts that originate from non-Western art are diverse art cultures. Diversified arts gradually move arts closer to racial, stratum, ethnic, and gender cultures and guide people understand the diversity of art culture. Diversified view of art education has the educational concept and common point of visual culture education.

The visual culture education in the United States developed rapidly in the late 1990s. With the development of post-modern visual culture and media, the visual environment is also changing. People begin to pay attention to ubiquitous visual images in life. Learners use the own life experiences as a starting point for art learning. Contemporaneous visual cultures reflect people's beliefs, attitudes, and values.

From a historical point of view, visual culture and education, in the category of art collectively referred to as pure art, the concept of culture is used multiple times to explore multiculturalism and understand multiculturalism in order to see the direction of visual culture education. The reality is connected together. In the recent school classrooms, students of different nationalities and nationalities are increasing. In this case, it means constantly emphasizing the necessity of multicultural education and not wearing colored glasses. Visual culture education needs to get rid of the single teaching mode and begin to explore from the background of understanding multiculturalism.

\subsection{The necessity of visual culture education.}

Various visual cultures such as TV, movies, the Internet, advertisements, shows, and games, including pure art, are widely used. These visual environments exist in these categories, and the boundaries are gradually blurred, with a variety of morphological changes. Visual image transmission is a two-way model that allows the public to respond to each other, and the main body of production becomes more and more diversified.

A large number of emerging visual cultures appear to be around us, but we do not have a critical awareness. This will have an impact on our emotions. Art education should adapt to the social and cultural environment of continuous change and development. It must also consider the impact on students' cultural forms and ideology.

Visual culture and education should cultivate the ability of aesthetic feelings. Second, visual culture education should emphasize the cultural and integrity of education. Third, visual culture education should use critical eyes to absorb and use diverse cultural images. Fourth, visual culture 
education and it is necessary to cultivate talents for future cultural industries. Fifth, visual culture education should make art life and make life full of happiness.

\section{Conclusion}

In appreciation of visual culture, the concept of art becomes different depending on the audience. Today, visual culture is not limited to pure art, but it is still based on the image of art. On the other hand, with the interpretation and understanding of art, the artistic value of visual culture is not only judged by artists and the critics, but different consumers can also judge by their own understanding. Visual culture education should be cautious in the selection of content and educational methods to develop practical teaching methods, and educators must have a spirit of continuous research.

\section{Acknowledgement}

Project: The inheritage and innovation of traditional handicraft in vocational and technical college--the tie dye in YunNan Bai nationality; Number of the project: 18 SB0697

\section{References}

[1] Kendall, A., \& Gal, Y. (2017). What uncertainties do we need in bayesian deep learning for computer vision? In Advances in Neural Information Processing Systems (pp. 5580-5590).

[2] Zhang, S., Wang, H., \& Huang, W. (2017). Two-stage plant species recognition by local mean clustering and Weighted sparse representation classification. Cluster Computing, 20(2), 1517-1525.

[3] Wong, W. K., \& Jiang, J. L. (2018). Computer vision techniques for detecting fabric defects. In Applications of Computer Vision in Fashion and Textiles (pp. 47-60).

[4] Zhang, S., Wang, H., Huang, W., \& Zhang, C. (2018). Combining Modified LBP and Weighted SRC for Palmprint Recognition. Signal, Image and Video Processing, 1-8.

[5] Leo, M., Medioni, G., Trivedi, M., Kanade, T., \& Farinella, G. M. (2017). Computer vision for assistive technologies. Computer Vision and Image Understanding, 154, 1-15. 